\title{
The Effect of Micro-Sized Carbon Material Mass Variation from Coconut Shell Leftovers Reinforced with Filter Paper towards Fe Filtration of Mataram Canal Water
}

\author{
Nur Baeity Andriyani, ${ }^{*}$ Buky Wahyu Pratama, Irnawati Widya Hastuti, and Wipsar Sunu Brams Dwandaru ${ }^{\dagger}$ \\ Physics Education Department, Faculty of Mathematics and Natural Sciences, \\ Universitas Negeri Yogyakarta, Karangmalang Complex, Yogyakarta, 55281
}

\begin{abstract}
The aim of this research is to determine the effect of micro-sized carbon material mass variation from coconut shell leftovers or wastes reinforced with filter paper towards Fe filtration of Mataram canal water. Preparation and synthesis of the micro-sized carbon material are conducted via liquid sonication exfoliation (LSE) method using two main type of equipments, i.e.: a blender and a self-custom made piezoelectric-based ultrasonication apparatus, and then incorporated into a simple filtration apparatus. UV-Vis spectroscopy characterization is done on the micro-sized carbon material solution, while atomic absorption spectroscopy (AAS) is done on samples of Mataram canal water before and after Fe filtration with a mass variation of the micro-sized carbon material. The UV-Vis results show that increasing the mass of the micro-sized carbon material increases the absorbance values at the same wavelength. The AAS results confirm that the greater the mass of the micro-sized carbon material the smaller the Fe content inside the water samples after filtration. The lowest Fe content of $0.016 \mathrm{ppm}$ is obtained for 3 grams of the micro-sized carbon material
\end{abstract}

KEYWORDS: micro-sized carbon material, coconut shell, Fe filtration, Mataram canal http://dx.doi.org/10.12962/j24604682.v13i3.2840

\section{INTRODUCTION}

Water is very important to sustain survival for all life forms on earth. Water plays an important role in meeting basic human needs. To ensure the community in terms of environmental health, water supply system that meets the quality of health is needed [1]. Therefore, it is necessary to provide water with a quality that meets the applicable clean water standards.

Mataram canal is an irrigation canal that connects Progo River in the west and Opak River in the east of Yogyakarta Special Region. The sewage is generally used as irrigation for rice fields that exist along the stream. However, nowadays Mataram canal is considered nothing more than just a dumpster, especially in the housing regions. Plenty of various wastes are often found floating in the water stream. The water quality of Mataram canal becomes very apprehensive, in addition to the water being dirty and turbid. These conditions resulted in less glory of Mataram canal as a part of Yogyakartas important historical site and potentially may cause health problems and pollutions for the surrounding environment.

Hence, real actions are needed to save and improve the water quality of the Mataram canal. The quality of water may be determined by several factors, including the level of metal

\footnotetext{
*E-MAIL: andribaeity@gmail.com

${ }^{\dagger}$ E-MAIL: wipsarianeuny.ac.id
}

contained in the water and clarity of water $[2,3]$. Therefore, it is necessary to take measures to improve the water quality by reducing the metal content until below the allowed threshold $[4,5]$. This usually requires filtering material as metal element absorber which can simultaneously reduce the color and odor of the water $[6,7]$. In this study, the micro-sized carbon material is synthesized from coconut shell wastes to be utilized as a filtering material for Mataram canal water. Carbon is the basic material of charcoal which is usually used in the filtration process to get clean water $[8,9]$. Coconut shell wastes are used as the source of carbon which is then exfoliated in liquid phase via blending and ultrasonication. The micro-sized carbon material obtained is then reinforced by filter paper and incorporated into a simple filtration apparatus.

\section{METHODS}

\section{Preparing the carbon powder}

Leftovers or wastes of coconut shells are gathered. The coconut shells are burnt until they become charcoals. The latter is smoothened by grinding until it becomes powder. The charcoal powder is ready for further processing.

\section{Preparing the self-custom made piezoelectric-based ultrasonication apparatus}

Cut a plywood board into a $4 \times 4 \mathrm{~cm}^{2}$ square shape of 9 pieces. Assemble 3 pieces of the square wooden boards into 


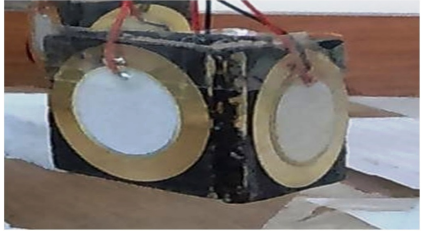

(a)

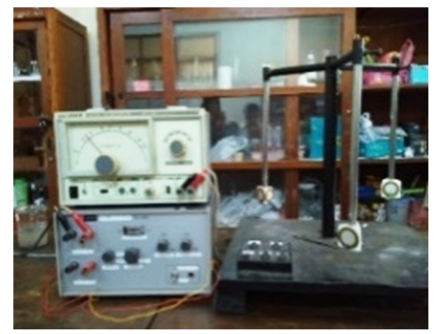

(b)

FIG. 1: Prism-like shape assembly of the piezoelectric-based ultrasonication probe (a), and the complete ultrasonication apparatus (b).

a prism-like shape, such that three prism-like shape assemblies are obtained. Next, paint the assemblies and dry them. Attach a piezoelectric tweeter probe onto each square-shaped plywood board surface as illustrated in the left picture of Figure 1. The final step is connecting the plywood board probe assemblies to the switches, an audio generator (Csi/SPECO SS-1), and an amplifier (Uchida TA-2MS) to become a complete ultrasonication apparatus shown in the right picture of Figure 1.

\section{Synthesizing the micro-sized carbon material}

Weigh the coconut shell charcoal powder as much as 20 grams using a digital scale. Next, mix commercial detergent, charcoal powder, and distilled water using a blender for $20 \mathrm{~min}$ utes. After blending, ultrasonicate the mixture for 4 hours at a frequency of $30 \mathrm{KHz}$, and then leave the mixture alone for 3 days in order to equilibrate. After settling down, take the sediment and heat it up to become micro-sized carbon material. Pour the micro-sized carbon material onto a filter paper. Pour distilled water onto the filter paper containing the microsized carbon material and then heat the filter paper until dry. The micro-sized carbon material reinforced with filter paper is ready to be used for filtration material.

\section{Assembling the filtration apparatus}

Prepare one pair of chopsticks, one circular jar, one rectangular jar, one circular canvas holder, and glue. Cut the chopsticks into 2 parts. Cut the open edge of the circular jar so it may fit the circular canvas holder and put a considerable hole on the bottom side for water entrance. Attach the filtration material (micro-sized carbon material reinforced with filter paper) onto the canvas holder. Stick the chopsticks on opposite sides of the circular jar using a glue gun and install the circular canvas holder on top of the circular jar. Finally, flip the circular jar such that the bottom (with a hole) is on the upper side, and plug it into the rectangular jar as shown in Figure 2.

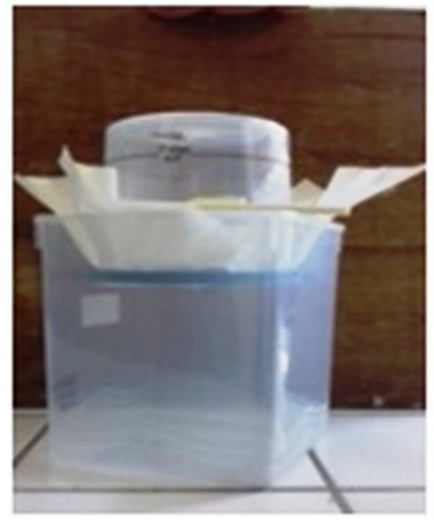

FIG. 2: The simple filtration apparatus.

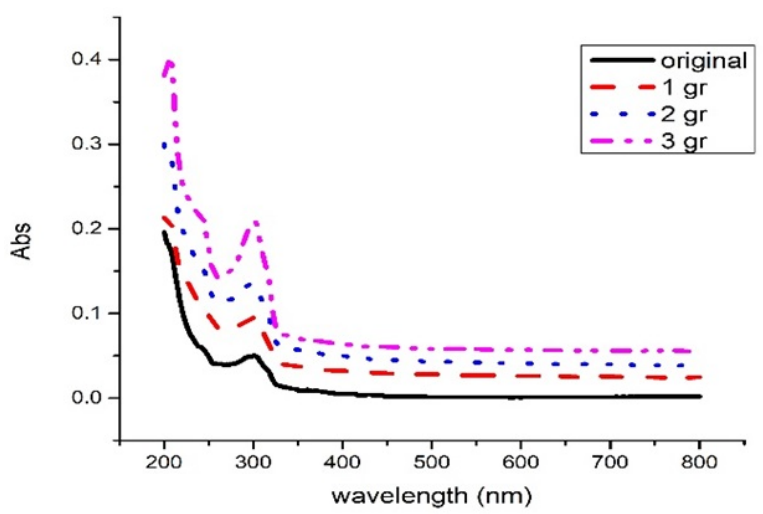

FIG. 3: UV-Vis graphs of micro-sized carbon material from coconut shell leftovers with a mass variation of 1,2 , and 3 grams.

\section{Filtration of Mataram canal water}

Pour the Mataram canal water sample as much as $250 \mathrm{ml}$ into the simple filtration apparatus (Figure 2) through the hole of the circular jar. The result of the filtration is gathered inside the rectangular jar. The water sample before and after filtration is tested for Fe content using AAS.

\section{RESULTS AND DISCUSSION}

UV-Vis characterization is performed to determine the absorbance of the solution at ultraviolet and visual wavelengths of light. The result of the characterization is shown in the graphical form of the relationship between absorbance and wavelength at $200-800 \mathrm{~nm}$. In this study, the mass variation of the coconut shell micro-sized carbon material is (in grams) 1; 2; and 3. The UV-Vis result can be seen in Figure 3.

The graphs which are presented in Figure 3 are the UVVis results of the coconut shell materials before and after the treatment to become micro-sized carbon material. The black line represents the characteristic of the coconut shell material before treatment. While the red, blue, and purple lines are graphs of coconut shell material as micro-sized carbon material with a mass variation of 1 gram, 2 grams, and 3 grams, 


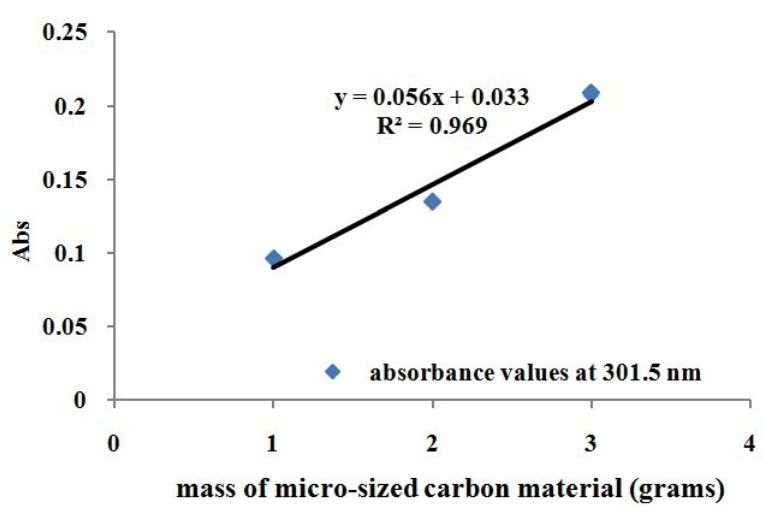

FIG. 4: A linear relation between the absorbance values at $301.5 \mathrm{~nm}$ with its corresponding micro-sized carbon material mass.

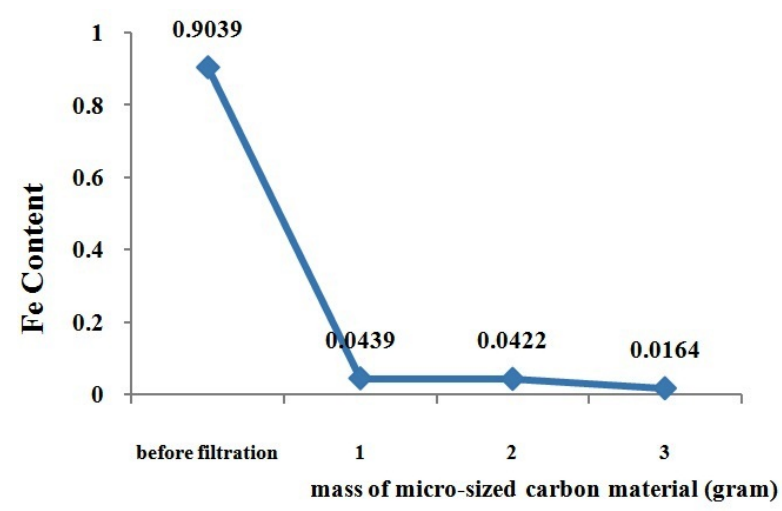

FIG. 5: The AAS results of Fe contents from water samples of Mataram canal before and after filtration treatment with the variation of micro-sized carbon materials of 1,2 , and 3 grams.

respectively. Figure 3 shows that all four graphs have the same peak at $301.5 \mathrm{~nm}$. The graphs are of similar shapes and have an increased absorbance value at the peak as the mass increases. The increase of the absorbance value at the peak while increasing the mass is also consistent with the LambertBeer's law. Moreover, the absorbance coefficient of the micro- sized carbon material is about $0.06 /$ grams, which is obtained via a linear relationship between the absorbance value at 301.5 $\mathrm{nm}$ and the corresponding mass of the micro-sized carbon material (Figure 4).

In this study, the water sample to test the filtration material comes from Mataram canal as much as $250 \mathrm{ml}$. The test is performed by measuring the Fe content of the Mataram canal water sample before and after being filtrated via the AAS equipment. The AAS results of Mataram canal water sample before and after treatment with the variation of the micro-sized carbon materials are given in Figure 5.

We may observe from Figure 5 that the water sample before filtration contains $0.9 \mathrm{ppm}$ of Fe metal. However, after the filtration treatment, the Fe content sharply decreases. For 1,2 , and 3 gram of micro-sized carbon materials, the Fe content decrease by $95.15 \%, 95.34 \%$, and $98.18 \%$, respectively, or decreases to $0.044 \mathrm{ppm}, 0.042 \mathrm{ppm}$, and $0.016 \mathrm{ppm}$, respectively. From these data, the iron content decreases compared to Mataram canal water sample before it is filtrated. This is due to the trapping of the iron metal in the form of ions by the micro-sized carbon material and binding of the iron metal to the compound attached to the micro-sized carbon material and into the material cavity [10]. Of course, the reinforced filter paper also plays a vital role in the trapping of Fe.

\section{CONCLUSION}

Micro-sized carbon filtration material has been produced using leftovers or wastes of coconut shells and reinforced with filter paper. The filtration material is then used to treat Mataram canal water in order to reduce the Fe content in the water sample. UV-Vis spectroscopy upon the micro-sized carbon material shows consistent absorbance peak of around $301.5 \mathrm{~nm}$ for all mass variation and satisfying the LambertBeer law. The AAS results indicate that the greater the mass of the micro-sized carbon material the smaller the Fe metal contains in the waste sample. the lowest Fe content of 0.016 ppm is obtained for 3 grams of micro-sized carbon material.
[1] P.H. Gleick, Ecological Applications, 8(3) 571-579 (1998).

[2] K.J. Pieper, M. Tang, and M. A. Edwards, Environ. Sci. Technol., 51(4), 2007-2014 (2017).DOI: 10.1021/acs.est.6b04034

[3] P.R. Costa, J.C. Martins, and P. Chainho, Impact of Invasions on Water Quality in Marine and Freshwater Environments in Impact of Biological Invasions on Ecosystem Services, Eds. M. Villa and P. E. Hulme, 221-234, Springer (2017). DOI: 10.1007/9783-319-45121-3-14.

[4] A. Alrajhi, S. Beecham, and A. Hassanli, Agricultural Water Management, 182, 117-125 (2017). DOI: 10.1016/ j.agwat.2016.12.011.

[5] B.-M. Yang, W.-L. Lai, Y.-M. Chang, Y.-S. Liang, and C.-M. Kao, Journal of Cleaner Production, 143, 1313-1326 (2017).
DOI: $10.1016 /$ j.jclepro.2016.11.105.

[6] D. Couillard, Water Research, 28(6), 1261-1274 (1994). DOI: 10.1016/0043-1354(94)90291-7.

[7] I. Gehrke, A. Geiser, and A. Somborn-Schulz, Nanotechnol. Sci. Appl., 8, 1-17 (2015). DOI: 10.2147/NSA.S43773.

[8] K. Mizuta, T. Matsumoto, Y. Hatate, K. Nishihara, and T. Nakanishi, Bioresource Technology, 95(3), 255-257 (2004). DOI: 10.1016/j.biortech.2004.02.015.

[9] A. Das, D. Sen, S. Mazumder, and A. K. Ghosh, AIP Conference Proceedings, 1832, 050094 (2017). DOI: 10.1063/1.4980327.

[10] J.C. Moreno-Pirajan and L. Giraldo, E-Journal of Chemistry, 9(2), 926-937 (2012). 